\title{
Penicillamine-induced virginal mammary hypertrophy
}

\author{
Daiwon Jun ${ }^{1}$, Na Rim Kim¹, \\ Young Chul Suh ${ }^{1}$, Young Jin Kim ${ }^{1}$, \\ Kyoung Soon $\mathrm{Cho}^{2}$, Jung Ho Lee ${ }^{1}$
}

Departments of ${ }^{1}$ Plastic and Reconstructive Surgery and ${ }^{2}$ Pediatrics, Bucheon St. Mary's Hospital, College of Medicine, The Catholic University of Korea, Bucheon, Korea

\begin{abstract}
Virginal mammary hypertrophy (VMH), also known as juvenile mammary hypertrophy, is characterized by excessive enlargement of the breasts. Especially in adolescent patients, this condition can cause a negative body image to develop and result in significant psychological stress. Furthermore, social problems can arise from difficulties in finding appropriately-fitting attire and having trouble exercising. Although the mechanism of $\mathrm{VMH}$ has not been fully elucidated, several associated drugs have been identified. In this report, we present a 15-year-old female patient with Wilson disease who developed macromastia after administration of penicillamine for 8 months. Despite cessation of penicillamine for 3 months, the condition remained stable; thus, reduction mammoplasty was performed. After surgery, the patient was able to return to activities of daily living. Although rare, physicians should be aware of the fact that penicillamine can cause VHM. Therefore, patients with Wilson disease should be checked regularly for changes in breast volume in order to minimize possible complications.
\end{abstract}

Keywords Wilson disease / Penicillamine / Breast disease

\section{INTRODUCTION}

Wilson disease is an autosomal recessive genetic disorder caused by the accumulation of copper within the human body. It is the most common inherited liver disease, and its symptoms may vary depending on the affected organs. In general, liver related symptoms such as fatigue, nausea and vomiting or jaundice develop in childhood whereas central nervous system related symptoms such as personality change or psychosis develop in late adulthood. Failure to excrete copper leads to various symptoms such as vomiting, weakness, itching, tremor, muscle stiffness, and psychosis, as the brain and liver are the most commonly involved organs.

Penicillamine is a metal antagonist that increases urinary copper excretion by chelation. The adverse effects of penicillamine are

Received: Oct 6, 2020 Revised: Oct 16, 2020 Accepted: Oct 26, 2020 Correspondence: Jung Ho Lee Department of Plastic and Reconstructive Surgery, Bucheon St. Mary's Hospital, College of Medicine, The Catholic University of Korea, 327 Sosa-ro, Wonmi-gu, Bucheon 14647, Korea Tel: +82-32-340-7059, Fax: +82-32-340-2544, E-mail: tfm0822@catholic. ac.kr

Copyright @ 2021 The Korean Society for Aesthetic Plastic Surgery.

This is an Open Access article distributed under the terms of the Creative Commons Attribution Non-Commercial License (https://creativecommons.org/licenses/by-nc/4.0/) which permits unrestricted non-commercial use, distribution, and reproduction in any medium, provided the original work is properly cited. www.e-aaps.org known to include irreversible neurologic deficits, hypersensitivity, marrow suppression, proteinuria, and teratogenic syndrome [1]. Although rare, virginal mammary hypertrophy $(\mathrm{VMH})$ induced by penicillamine has been reported [2]. In this report, we would like to share our experience of the diagnosis and treatment of penicillamine-induced VMH that developed in a patient with Wilson disease.

\section{CASE REPORT}

A 14-year-old female patient was admitted to a pediatrics department for the evaluation of elevated liver enzyme levels. After a genetic study, Wilson disease was confirmed. At that point, the patient's body mass index (BMI) was $22.14 \mathrm{~kg} / \mathrm{m}^{2}$ (height, $156.8 \mathrm{~cm}$; weight, $54.5 \mathrm{~kg}$ ). Trientine treatment was first commenced with $500 \mathrm{mg}$ twice a day. Because trientine must be stored at $2^{\circ} \mathrm{C}$ to $8^{\circ} \mathrm{C}$, the patient showed low adherence to the medication during the first month of therapy. Thus, the medication was altered to penicillamine and was continued for 8 months at a dose of $500 \mathrm{mg}$ twice a day. Four months after the patient started penicillamine, breast enlargement was noticed. The medication was maintained and the patient's breasts continued to grow, which eventually resulted in difficulty with activities of daily living. The medication was then switched to $500 \mathrm{mg}$ of trientine twice a day for 3 months, but the condition remained stable. At the age of 15 , the patient was trans- 
ferred to our department for reduction mammoplasty (Fig. 1). Due to large breasts, she had difficulty in wearing clothes and suffered from neck and shoulder pain. Preoperative physical examination shows marked hypertrophy of both breasts with grade 3 breast ptosis. The patient's BMI was $22.43 \mathrm{~kg} / \mathrm{m}^{2}$ (height, $157 \mathrm{~cm}$; weight, $55.3 \mathrm{~kg}$ ). The right midclavicle to nipple distance was $36 \mathrm{~cm}$, the

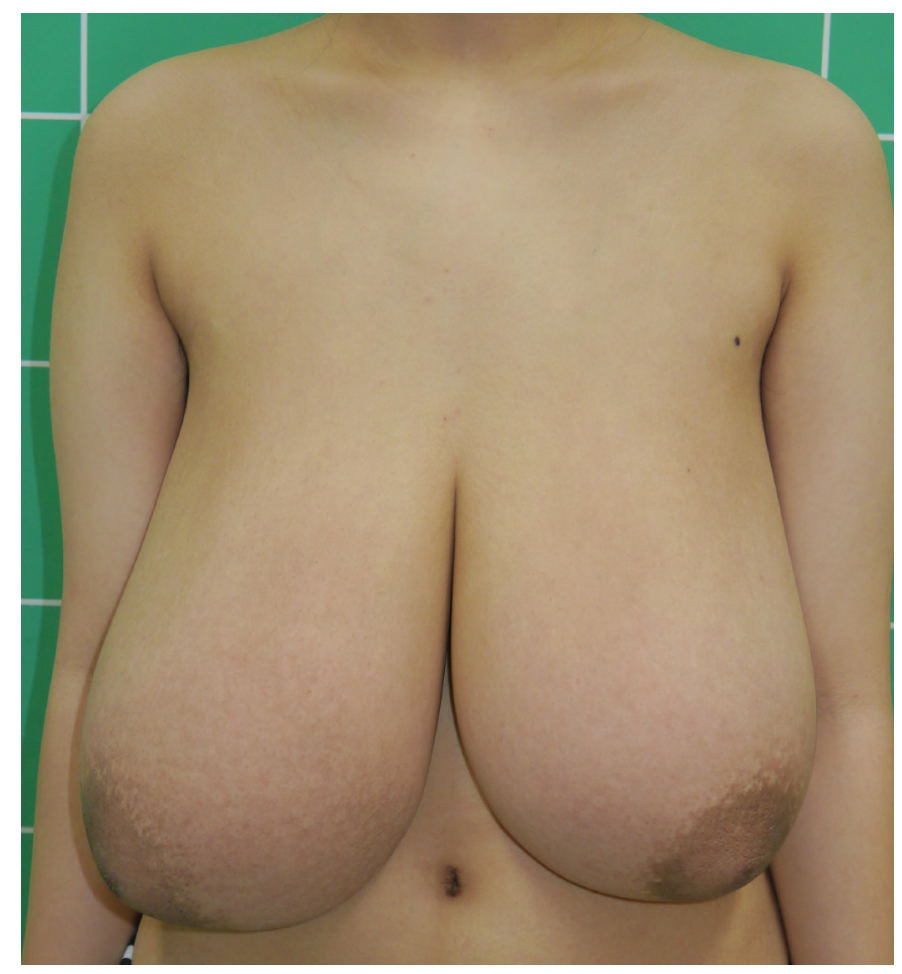

Fig. 1. Preoperative photograph. Breast hypertrophy with a larger right breast was noted. sternal notch to nipple distance was $37 \mathrm{~cm}$, and the nipple to inframammary fold distance was $17 \mathrm{~cm}$. The left midclavicle to nipple distance was $34 \mathrm{~cm}$, the sternal notch to nipple distance was $35 \mathrm{~cm}$, and the nipple to inframammary fold distance was $19 \mathrm{~cm}$. Because both the patient and her guardians sought to minimize postoperative scarring, short-scar periareolar inferior pedicle reduction mammoplasty with a pedicle width of $8 \mathrm{~cm}$ was performed. The amount of excision was $974 \mathrm{~g}$ for the right breast and $858 \mathrm{~g}$ for the left breast (Fig. 2). The findings of a pathologic study were consistent with VMH (Fig. 3). Seven months after surgery, no sign of recurrence or loss of nipple sensation was noticed (Fig. 4). The patient's BMI was $20.28 \mathrm{~kg} / \mathrm{m}^{2}$ (height, $157 \mathrm{~cm}$; weight, $50 \mathrm{~kg}$ ). The patient could return to activities of daily living without difficulties.

\section{DISCUSSION}

The differential diagnosis of mammary hyperplasia in adolescents includes pregnancy, fibrocystic disease, adolescent macromastia, virginal (or juvenile) mammary hypertrophy, and other tumorous conditions such as fibroadenoma and phyllodes tumor [3].

$\mathrm{VMH}$ is rare and involves an atypical, alarmingly rapid growth of breast tissue during puberty. This enlargement may be unilateral or bilateral, and can occur at any time during puberty. The underlying mechanism of $\mathrm{VMH}$ is not clear, but drugs such as neothetazone, cyclosporine, penicillamine, and prednisolone are known to trigger the development of mammary hyperplasia [4]. Penicillamine, a chelating agent of copper, is a drug used for the treatment of Wilson disease, rheumatoid arthritis, and systemic sclerosis. The adverse effects of penicillamine include bone marrow suppression, obliterating bronchiolitis, nephritis syndrome, thyroiditis, and polyneuropathy. Breast enlargement is a rare complication, of which
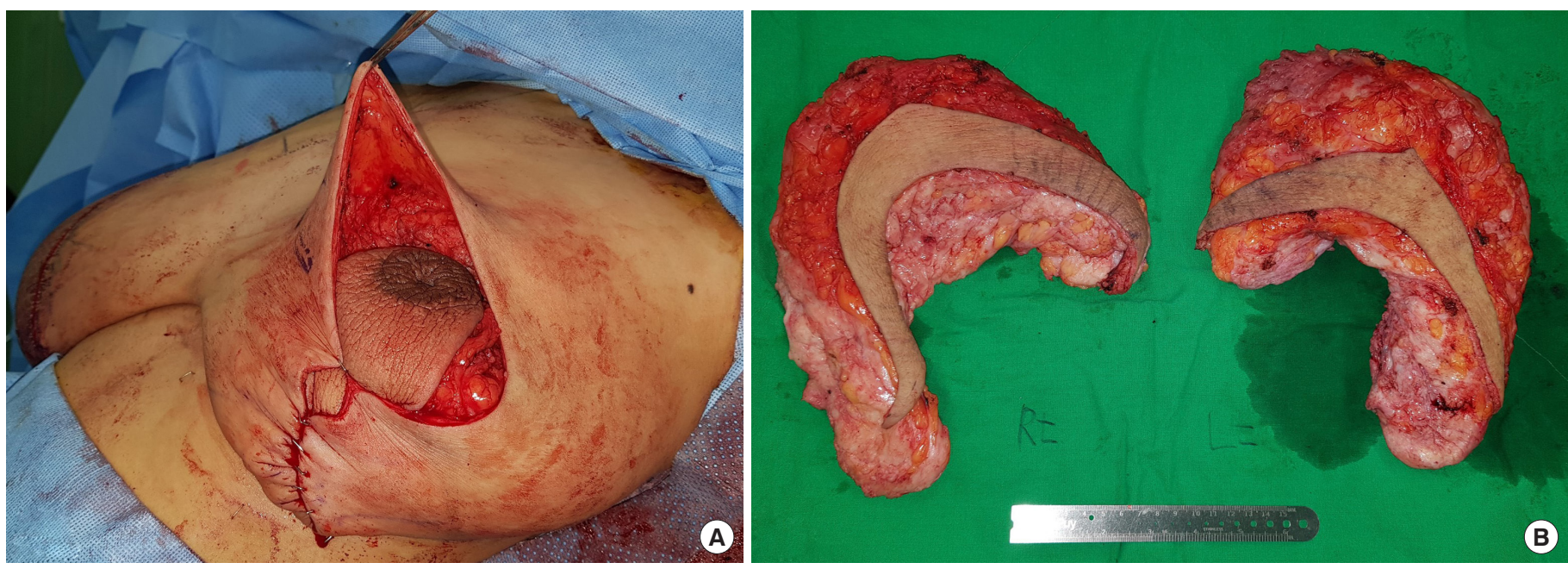

Fig. 2. Intraoperative photos. (A) Short-scar periareolar inferior pedicle reduction mammoplasty was performed. (B) The amount of excision was $974 \mathrm{~g}$ for the right breast and $858 \mathrm{~g}$ for the left breast. 

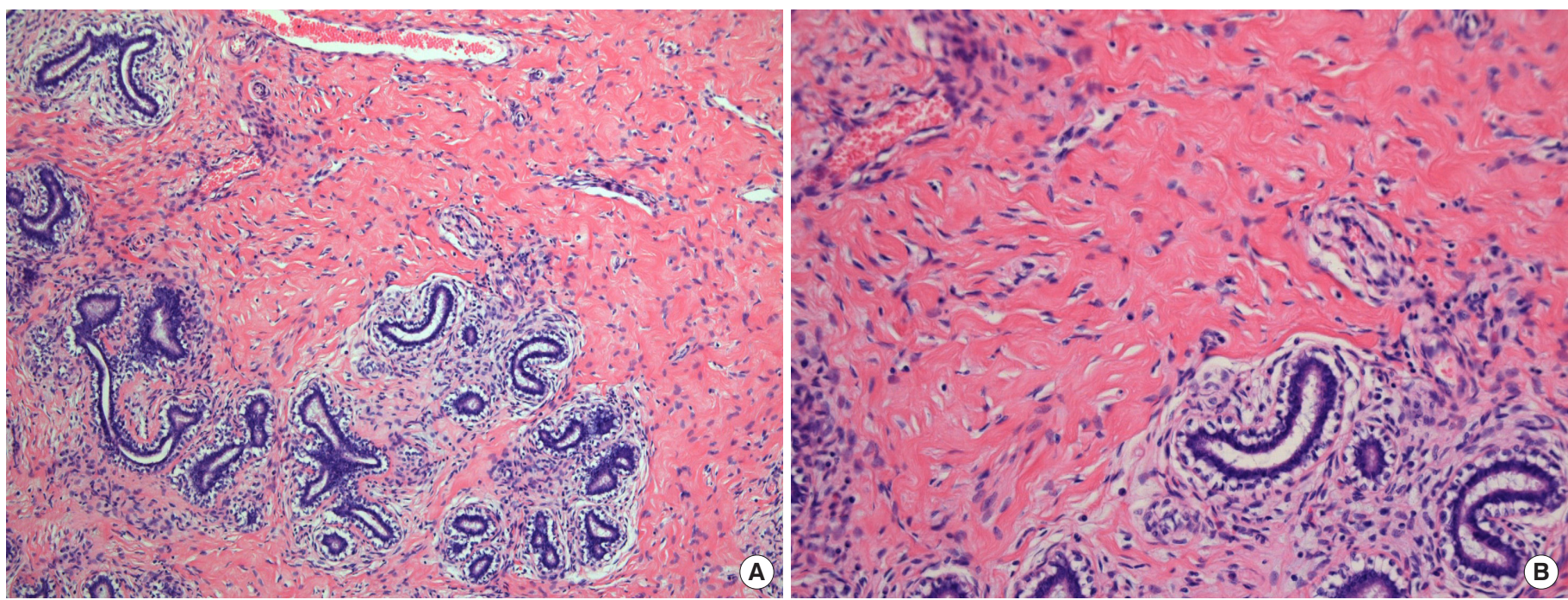

Fig. 3. Histopathologic appearance of the excised left breast tissue. Proliferation of both tubular ductal structures and stromal connective tissue can be noted on hematoxylin and eosin staining $(A, \times 100 ; B, \times 200)$.

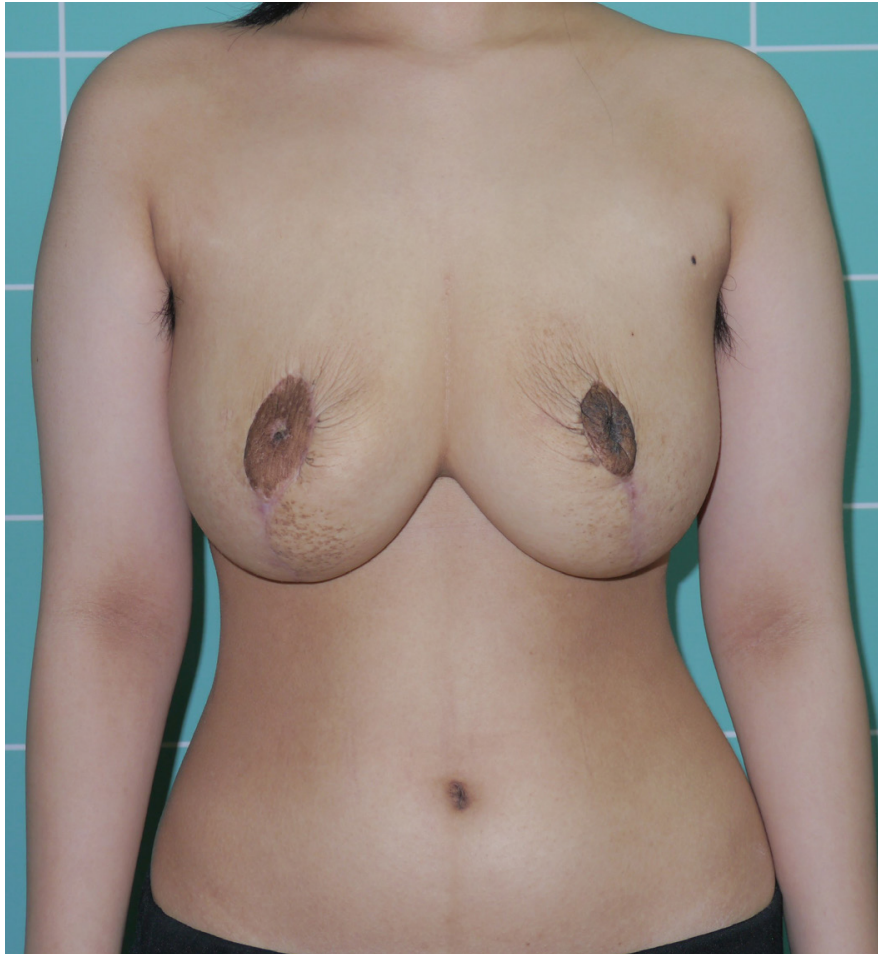

Fig. 4. Photograph at 7 months after surgery.

only a few cases have been reported [5]. Because of its adverse effects, penicillamine is now considered as a second-line drug after trientine [6]. The mechanism through which penicillamine induces breast hypertrophy has not yet been clarified. It is suspected that penicillamine might alter the level of circulating prolactin or the susceptibility of mammary glands to prolactin [7]. The interval be- tween administration of penicillamine and breast hypertrophy ranges from 12 weeks to 18 months [2].

Because of rapid breast growth, VMH patients usually present with neck pain, shoulder pain, or back pain [8]. Skin irritation or intertrigo are also frequently seen along brassiere straps. Furthermore, patients suffer from significant emotional stress, which can result in dissatisfaction with their body image and poor self-esteem. Since Wilson disease is usually diagnosed in childhood or early adolescence, this could pose a critical issue.

Because of the rarity of the disease, there is no evidence-based treatment protocol for drug-induced VMH. One study reported that discontinuation of penicillamine and administration of danazol resulted in regression of breast hypertrophy [9]. Attempts to control breast growth through hormonal agents including bromocriptine, medroxyprogesterone, and tamoxifen have been tried, but the results were inconsistent [10]. If medical treatment is unsuccessful, reduction mammoplasty can be considered. Although breast reduction is an effective and relatively safe procedure, both the patient and her guardians should be involved in the decision-making process. Detailed information regarding the operation should be provided prior to surgery. If the patient is not motivated, caution is needed not to hasten the procedure.

Reduction mammoplasty can produce immediate relief of physical symptoms and psychological improvements. However, the risk of loss of nipple sensation and inability to carry out breastfeeding should be addressed prior to surgery. A previous study has shown that the success rate of breastfeeding after reduction mammoplasty is not significantly different depending the type of pedicle (62\%, $65 \%$, and $64 \%$ for superior, medial, and inferior pedicle techniques, respectively) [11]. Only $2 \%$ of patients report impaired or complete loss of nipple sensation after reduction mammoplasty. 
Because the breasts naturally grow during puberty, adolescent patients with Wilson disease may not perceive the adverse effect of penicillamine. For this reason, a close observation of breast volume is required for physicians treating patients with penicillamine. In addition, surgeons should consider breast reduction for patients with VMH suffering from physical and emotional distress.

\section{NOTES}

\section{Conflict of interest}

No potential conflict of interest relevant to this article was reported.

\section{Ethical approval}

The study was exempted from ethical approval (exemption approval No. HC20ZASI0211).

\section{Patient consent}

The patient provided written informed consent for the publication and the use of her images.

\section{ORCID}

Daiwon Jun

Na Rim Kim

Young Chul Suh

Young Jin Kim

Kyoung Soon Cho

Jung Ho Lee
https://orcid.org/0000-0003-4713-333X

https://orcid.org/0000-0002-6046-4566

https://orcid.org/0000-0002-0320-3933

https://orcid.org/0000-0002-9046-9907

https://orcid.org/0000-0002-0212-0992

https://orcid.org/0000-0002-3800-5494

\section{REFERENCES}

1. Munro R, Capell HA. Penicillamine. Br J Rheumatol 1997;36:104-9.

2. Desautels JE. Breast gigantism due to D-penicillamine. Can Assoc Radiol J 1994;45:143-4.

3. Wolfswinkel EM, Lemaine V, Weathers WM, et al. Hyperplastic breast anomalies in the female adolescent breast. Semin Plast Surg 2013;27: 49-55.

4. O’Hare PM, Frieden IJ. Virginal breast hypertrophy. Pediatr Dermatol 2000;17:277-81.

5. Sakai Y, Wakamatsu S, Ono K, et al. Gigantomastia induced by bucillamine. Ann Plast Surg 2002;49:193-5.

6. Brewer GJ. Recognition, diagnosis, and management of Wilson's disease. Proc Soc Exp Biol Med 2000;223:39-46.

7. Rose BI, LeMaire WJ, Jeffers LJ. Macromastia in a woman treated with penicillamine and oral contraceptives: a case report. J Reprod Med 1990;35:43-5.

8. Fisher W, Smith JW. Macromastia during puberty. Plast Reconstr Surg 1971;47:445-51.

9. Taylor PJ, Cumming DC, Corenblum B. Successful treatment of Dpenicillamine-induced breast gigantism with danazol. Br Med J (Clin Res Ed) 1981;282:362-3.

10. Dancey A, Khan M, Dawson J, et al. Gigantomastia: a classification and review of the literature. J Plast Reconstr Aesthet Surg 2008;61:493502.

11. Cruz NI, Korchin L. Lactational performance after breast reduction with different pedicles. Plast Reconstr Surg 2007;120:35-40. 